\title{
Review
}

Journal of Innate

Immunity
J Innate Immun 2014;6:272-283

DOI: $10.1159 / 000358835$
Received: January 16, 2014

Accepted after revision: January 20, 2014 Published online: February 12, 2014

\section{The Meta-Genome of Sepsis: Host Genetics, Pathogens and the Acute Immune Response}

\author{
John H. Boyd $d^{a, b}$ James A. Russell ${ }^{a, b}$ Chris D. Fjell ${ }^{b}$ \\ ${ }^{a}$ Division of Critical Care Medicine, St. Paul's Hospital, and ${ }^{b}$ Centre for Heart Lung Innovation, \\ University of British Columbia, Vancouver, B.C., Canada
}

\section{Key Words}

Genetics · Sepsis · Gene expression · Meta-genome ·

Microbiome

\begin{abstract}
Severe infection and the patient response constitute sepsis. Here, we review the meta-genome (patient genetics, pathogen communities and host response) and its impact upon the outcome of severe sepsis. Patient genetics, both predisposition for infection and the subsequent response to infection are reviewed. The pathogen is discussed with particular emphasis upon the modern era of microbiome analysis and nucleic acid diagnostics. Finally, we discuss the host clinical and immune responses and present new data to suggest that the immune response is the key to understanding sepsis and improving a death rate of nearly $30 \%$.
\end{abstract}

(c) 2014 S. Karger AG, Basel

\section{The Clinical Presentation and Treatment of Sepsis}

Sepsis is a sequela of bacterial infections that kills more than 200,000 people in North America annually. According to the Surviving Sepsis group [1], the number of cases globally reaches 18 million/year (http://www.survivingsepsis.org/), and with a mortality rate of $30-35 \%$ it is one of the leading causes of death worldwide. Sepsis is a clinical response to a suspected or proven infection and is defined by two or more of the following SIRS signs: tachypnea, tachycardia, leukocytosis or leukopenia, and hyperthermia or hypothermia [2]. Severe sepsis is sepsis plus a new organ dysfunction due to sepsis [2].

\section{Clinical Presentation: Host Response}

In early sepsis, a strong inflammatory response is triggered due to innate recognition of microbial signature molecules by pattern recognition receptors [3]. We have recently shown that at least 39 cytokines, chemokines and growth factors are highly regulated during this period [4, 5] (table 1). In cases of severe sepsis, the inflammation is more intense, and there are greater plasma levels of cytokines accompanied by a heightened physiologic response and secondary organ dysfunction $[4,5]$. In the most extreme cases, a vicious cycle revolving around inflammation and coagulation leads to multiple organ failure and death within hours to days. The threat to organ function posed by the systemic hyperinflammatory response has

\section{KARGER}

E-Mail karger@karger.com

www.karger.com/jin
(C) 2014 S. Karger AG, Basel

$1662-811 \mathrm{X} / 14 / 0063-0272 \$ 39.50 / 0$
Dr. John H. Boyd

Centre for Heart Lung Innovation, St. Paul's Hospital

Room 166, 1081 Burrard Street

Vancouver, BC V6Z 1Y6 (Canada)

E-Mail John.Boyd@hli.ubc.ca 
Table 1. Names and abbreviations of cytokines, chemokines and growth factors

\begin{tabular}{|c|c|}
\hline EGF & epidermal growth factor \\
\hline Eotaxin & eotaxin \\
\hline FGF-2 & basic fibroblast growth factor \\
\hline Flt-3 ligand & Fms-related tyrosine kinase 3 ligand \\
\hline Fractalkine & fractalkine \\
\hline G-CSF & granulocyte colony-stimulating factor \\
\hline GM-CSF & $\begin{array}{l}\text { granulocyte-macrophage } \\
\text { colony-stimulating factor }\end{array}$ \\
\hline GRO & CXCL1 \\
\hline IFN- $\alpha_{2}$ & interferon- $\alpha_{2}$ \\
\hline IFN- $\gamma$ & interferon- $\gamma$ \\
\hline IL-10 & interleukin-10 \\
\hline IL-12 (p40) & interleukin-12 (p40 subunit) \\
\hline IL-12 (p70) & interleukin-12 (p70 subunit) \\
\hline IL-13 & interleukin-13 \\
\hline IL-1 & interleukin-1 \\
\hline IL-17 & interleukin-17 \\
\hline IL-1ra & interleukin-1 receptor antagonist \\
\hline IL-1a & interleukin-1a \\
\hline IL- $1 \beta$ & interleukin- $1 \beta$ \\
\hline IL-2 & interleukin-2 \\
\hline IL-3 & interleukin-3 \\
\hline IL-4 & interleukin-4 \\
\hline IL-5 & interleukin-5 \\
\hline IL-6 & interleukin-6 \\
\hline IL-7 & interleukin-7 \\
\hline IL-8 & interleukin-8 \\
\hline IL-9 & interleukin-9 \\
\hline IP-10 & CXCL10 \\
\hline MCP-1 & CCL2 \\
\hline MCP-3 & CCL7 \\
\hline MDC & CCL22 \\
\hline MIP-1a, MIP-1 & macrophage inflammatory protein $-1 \alpha$ \\
\hline TGF- $\alpha$ & transforming growth factor- $\alpha$ \\
\hline TNF- $\alpha$ & tumor necrosis factor- $\alpha$ \\
\hline TNF- $\beta$ & tumor necrosis factor- $\beta$ \\
\hline VEGF & vascular endothelial growth factor \\
\hline sCD40L & soluble CD40-ligand \\
\hline sIL-2R $\alpha$ & soluble IL-2 receptor- $\alpha$ \\
\hline
\end{tabular}

been thought to explain the subsequent shift towards an immune-suppressed state. This progression to an immunodepressed phenotype has been implicated as a cause of secondary infections. Characteristics of the immunosuppressive stage include anergy, lymphopenia, hypothermia and nosocomial infections. There is an increase in circulating anti-inflammatory cytokines such as IL-10, apoptosis of B and CD4+ T lymphocytes [6], an increased fraction of regulatory $\mathrm{T}$ lymphocytes [7], and markedly decreased expression of monocyte HLA-DR. This second phase of sepsis is thought to explain the high subacute mortality associated with sepsis. Clinicians could potentially treat either the early hyperimmune organ failure or the later immunosuppressed state of patients with either potent immunosuppressants, such as corticosteroids, or selective immune adjuvants (or antibiotics), respectively. However, prevention of immunosuppression is not currently possible given uncertainties regarding accurate clinical and laboratory assessment of immune status.

Possibly due to this inability to determine real-time immune status in clinical settings, randomized controlled trials (RCTs) of both immune suppressants and immune adjuvants have been uniformly disappointing. For example, RCTs have been performed in which the approach was to render circulating immune-modulatory factors such as bacterial products invisible to the immune system using intravenous pooled immune globulin (IVIG). However, while numerous small studies of IVIG treatment in septic shock appeared to improve mortality [8], a large multicenter RCT did not show a mortality benefit in patients randomized to IVIG [9].

During the 1980s and before, the predominant organisms responsible for severe sepsis and septic shock were Gram-negative bacteria $[10,11]$; thus, most therapies targeted cell wall components of these organisms. The first line of antiendotoxin therapy was a lipid A-specific antibody HA-1A. A multicenter RCT of HA-1A in septic shock showed no survival benefit in these very sick patients [12]. In 2000, 2 large RCTs of a murine antiendotoxin antibody to [13], and separately an antibody against Enterobacteriaceae common antigen [14] in patients in septic shock found no survival advantage to either therapy.

TNF- $\alpha$ can reproduce many of the key physiologic derangements seen in early sepsis, thus spurring numerous RCTs using neutralizing antibodies to TNF- $\alpha$ and its receptor [15-19]. Despite excellent neutralization of the biologic activity of TNF- $\alpha$, none of these RCTs found a survival advantage with TNF- $\alpha$ neutralization treatment.

Steroids are the cornerstone of therapy for acute (nonspecific) inflammation such as exacerbations of asthma. In the 1980s, 3 RCTs examined high-dose $(30 \mathrm{mg} / \mathrm{kg}$ methylprednisolone) steroids in patients with septic shock [20-22]. All of these failed to show a survival benefit to those randomized to receive intravenous steroids, but did demonstrate a trend to faster resolution of shock (discontinuation of vasopressors) at the cost of increased secondary/nosocomial infections. More recent well-powered RCTs have used lower, less immunosuppressing doses of steroids (in part to treat acute adrenal insufficiency), and have provided conflicting results as to the 
benefits associated with steroid therapy [23, 24]. The French RCT of Annane et al. [23] found that patients who had an abnormal adrenal axis (as assessed by ACTH stimulation test) who received corticosteroids (hydrocortisone plus fludrocortisone) had higher survival than patients on placebo. In distinct contrast, the later CORTICUS RCT found no difference in survival between corticosteroid and placebo-treated patients overall or in the patients who had an abnormal ACTH stimulation test [24]. The most recent Surviving Sepsis Guideline [25] suggests 'consideration' of corticosteroids only for patients with refractory septic shock.

\section{Clinical Presentation: Infectious Organism}

Our sepsis research group at UBC led one of the largest RCTs of septic shock, the Vasopressin in Septic Shock Trial (VASST) [26]. While the intervention tested was vasopressin plus norepinephrine versus norepinephrine alone, clinical and microbiological data were collected regarding the definite and presumably causative infectious organisms. In 778 patients admitted with septic shock at 27 centers across Canada, the USA and Australia in VASST, only $26 \%$ of blood cultures identified an infection in the VASST cohort, and only $57 \%$ of cultures from the primary site, e.g. sputum culture from pneumonia patients, grew an identifiable organism. In those for whom timed data were available (patients recruited at our institution), there was a median delay of $30 \mathrm{~h}$ from meeting shock criteria until preliminary standard microbiology report of cultures with identification of the generic organism type (e.g. Gram-positive cocci). A further delay of 24-48 h occurred in speciating the organism (e.g. Staphylococcus aureus), and determining antibiotic resistance (e.g. MRSA). In our view, this delay (24-48 h or more) and lack of accuracy in precise organism identification of infectious organism(s) in patients who have septic shock is completely inadequate in septic shock because inappropriate antibiotic selection increases the relative risk of dying by as much as $8 \%$ per hour [27-30]. Thus, technique(s) to rapidly and accurately identify the infecting organism(s) could lead to earlier more accurate antibiotic selection in septic shock. We emphasize that it is not only the delays to microbiology results reporting, but the very low sensitivity of traditional microbial culture, which thwarts accurate microbial diagnosis. In a disease with a stunning $15 \%$ mortality in the first 2 days and $25-35 \%$ by 28 days, the clinician receives no new diagnostic information throughout the critical very early phase of disease and treatment. Furthermore, in the era of the microbiome, it has become very obvious that only a fraction of potentially pathogenic organisms can be cultured in standard media [31-33], i.e. current clinical microbiology testing is likely very insensitive. This low sensitivity suggests that that treating physicians often do not know the true cause(s) of severe infection. Furthermore, this lack of early accurate microbiologic diagnosis also impairs our evaluation and understanding of unique host factors that influence therapeutic success in septic shock. To restate, we suggest that better outcomes of septic shock could be achieved by (1) early accurate organism identification paired with (2) early accurate host genomic, immunity evaluation - the essence of the metagenomic approach.

\section{Sepsis in the Era of the Meta-Genome}

\section{Host Genetics and Risk of Infection}

Human host genetics may determine the risk of acquiring an infection (i.e. a relative immunodeficiency). While some disorders such as severe combined immunedeficiency reflect rare mendelian genetic mutations in the common gamma chain, adenosine deaminase or other more rare mutations, these mutations are invariably detected in childhood due to recurrent serious infections. In adults with no known immune-deficiency, it is more challenging to determine which (if any) genetic polymorphisms lead to an increased risk of acquiring infection, mainly due to the challenge of determining exposure to the pathogen(s). Despite this inherent limitation of delayed, insensitive organism identification, some polymorphisms appear to confer increased risk to specific pathogens. For example, polymorphisms in the known innate immune molecule Toll-like receptor 2 and the anti-infective cytokine IL-17A gene increase the risk of serious Gram-positive infections [34, 35]. A polymorphism in CD14, a key molecule in the innate immune response to Gram-negative endotoxin has been found to increase the risk of serious Gram-negative infections [34], while polymorphisms in the complement-activating mannosebinding lectin results in increased serious infections [34]. A functional polymorphism of IRAK4 increases the risk of Gram-positive infections in childhood and in adult septic shock [36].

The risk of acquiring specific pathogens also appears to be influenced by human host genetic variation. For instance, Neisseria meningitidis infection is detected more frequently in humans with polymorphisms in IL-1 and 
TNF- $\alpha$ genes [37], while polymorphisms in the inflammasome gene CARD-8 increase the risk of mycobacterial infection in HIV+ patients [38].

Human host genetic variation may also influence the response to an infection, including the degree of immune activation and secondary organ failure. In the innate immune response, haplotype clades in the integrative inflammatory cytokine IL-6 increase the risk of organ failure and death in those who present with a severe infection [39], while polymorphisms in IL-8, protein C and NFkBinducing kinase are associated with increased and more severe organ failure complicating septic shock [40-43]. Because treatment of septic shock is largely supportive, aimed at early broad-spectrum (often nonspecific antibiotics), normalizing blood pressure and organ perfusion [25], polymorphisms in genes active in the vasopressor response are also associated with increased risk of organ dysfunction. A polymorphism in the beta-2 adrenergic receptor gene known to confer hyposensitivity to catecholamines necessitates higher doses of vasopressors and increases mortality [44]. A variant in the gene responsible for clearing vasopressin from plasma (LNPEP also known as vasopressinase) alters the pharmacokinetics of vasopressin infusion and increases the risk of death from septic shock [45]. Polymorphisms in the negative regulator of the angiotensin II receptor (AGTRAP) are also associated with increased mortality and blood pressure in patients with septic shock [46].

While these relatively common human host genetic variants (polymorphisms) influence both the susceptibility to and outcome from infection, there are to date no biomarkers that are predictive of response to drugs used in septic shock in part because of the paucity of novel therapeutics in severe sepsis and septic shock.

\section{The Roles of the Infecting Pathogen}

The true ecology at the site of infection and circulating bacterial 'load' has yet to be defined in sepsis. The current use of a binary approach to culture (positive vs. negative) does not quantitate the bacterial density or provide evidence of all organisms present in the presumably infected materials [47]. Bacterial growth in cultures, if it happens, typically does not occur for several hours to days, and later sensitivity reporting does not occur until 24-48 h into the course of severe sepsis and septic shock [48]. Moreover, blood cultures in particular lack sensitivity and are positive only $30 \%$ of the time in cases of sepsis [47]. Molecular diagnostics of the infect- ing pathogens represent a novel method to assess and diagnose the breadth of specific bacterial species and their density (often also called 'bacterial load' or 'burden').

\section{Pathogen Density in Circulating Blood}

Higher bacterial loads predict worse outcome in infections including Gram-negative sepsis [49], methicillinresistant $S$. aureus bacteremia [50] and bacterial meningitis $[51,52]$. Thus, bacterial load could be conceived as and indeed is used as a prognostic biomarker. At this stage, there is equipoise as to which method (traditional culture or molecular diagnostics) is most representative of the biological 'truth'. Regarding molecular diagnostic approaches, there appears to be a threshold level below which infecting organism nucleic acid detection cannot detect bacterial DNA. PCR of bacterial DNA appears most sensitive currently. However, PCR fails to detect organisms identified by standard microbial culture between 20 and $30 \%$ of the time [47]. In another cohort study, a universal bacterial detection method using 16S PCR was positive in only $50 \%$ of positive blood cultures [53]. A later prospective cohort study compared the diagnostic accuracy of $16 \mathrm{~S}$ rDNA detection in bacterial meningitis, early-onset neonatal sepsis and spontaneous bacterial peritonitis [54]. The molecular strategy was more accurate than conventional cultures for bacterial meningitis and neonatal sepsis but gave notably worse results (i.e. decreased sensitivity) for the peritoneal fluid of patients with possible spontaneous bacterial peritonitis. Thus, most clinicians do not appreciate that PCR has a lower rate of contamination than blood cultures likely because of the need for a higher bacterial load for $16 \mathrm{~S}$ rDNA detection than conventional blood culture [55]. Recently, the potential for quantitative PCR testing in organisms which are difficult to culture (e.g. Acinetobacter baumannii) was highlighted in a prospective cohort study that used bacterial load measurements to modify ongoing antibiotic treatment in critically ill patients with A. baumannii bacteremia [56]. Bacterial loads in this study were correlated with successful bacterial clearance defined by clinical laboratory microbiology and informed the treating team when it was appropriate to discontinue antibiotics. Thus, it appears that if an alternate technology with higher sensitivity to PCR to detect a pan-pathogen nucleic acid region were available, there could be rapid adoption of such testing to be used as a predictive biomarker to guide antibiotic therapy. 


\section{The Microbiome at the Site of Infection and in Blood}

Current PCR-based techniques are limited in identifying unique pathogens in blood due to the relatively low abundance of bacteria. Commercially available multiplex PCR microbial detection kits are licensed to detect pathogen DNA directly from blood and are approved for clinical use in Europe [57]. Implementation of multiplex PCR microbial detection kits yields earlier pathogen detection as well as pathogen detection despite negative conventional microbial cultures [58-60]. However, results of multiplex PCR tests are not unequivocally better than blood cultures because of difficulty in assigning the 'gold standard of infection' [29-31]. In a study of 245 patients with possible sepsis [32], a multiplex PCR kit provided results in $24 \mathrm{~h}$ compared to $68 \mathrm{~h}$ for blood culture, and had a significantly higher positive microbial detection rate than blood cultures (30 vs. 14\%). However, regarding specificity, only 17 of 53 positive blood cultures were reproduced as positive by PCR. Further clouding the validity of these molecular approaches is the notion that pathogen identification from blood (by culture or molecular methods) almost certainly underestimates the true breadth of the microbial community (microbiome) at the site of infection. For instance, it is now known that gut microbiome contains hundreds of species of bacteria [61-63]. In patients who had perforated colon in the VASST study of septic shock, the median number of cultured organisms in both blood and peritoneal fluid was just 2 [26]. At most, 4 organisms were identified through bacterial culture. Traditional culture clearly underestimates the biodiversity of the infecting bacterial community.

Thus, our review of the literature and our exploration of the VASST study lead to our overarching hypothesis that $16 \mathrm{~S}$ bacterial rRNA sequencing might have a role in accurately defining bacterial species at the site of infection where the density of pathogens is much higher than in blood.

\section{The Microbiome of Community-Acquired Pneumonia}

Accordingly, from 2011 to 2013, we enrolled 40 patients with severe community-acquired pneumonia and 14 noninfected elective preoperative control patients from whom we obtained sputum and tracheal aspirates (at the time of intubation), respectively, in a prospective cohort study approved by the Providence Health Care Research Ethics Board. $10 \mathrm{ml}$ of sterile saline was instilled into the endotracheal tube at intubation and $5 \mathrm{ml}$ aspirated into a sterile container. Standard curves for RTqPCR were constructed from DNA extracted from Escherichia coli $\mathrm{DH} 5$ a bacteria grown in LB broth, using DNeasy kit (QIAGEN, 69506) comparing cycle threshold versus copy number in which DNA is diluted 10-fold from $9.92 \times 10^{-7}$ to $9.92 \times 10^{-1} \mathrm{ng} / \mu \mathrm{l}$ (corresponding to $1,000,000$ to 1 bacterial genomes). Real-time PCR (qPCR) was performed on the ViiA7 system (Applied Biosystems) for a 466-bp fragment of the bacterial $16 \mathrm{~S}$ ribosomal DNA that was amplified using the forward primer $5^{\prime}$-TCCTACGGGAGGCAGCAGT-3', and 5'-GGACTACCAGGGTATCTAATCCTGTT- $3^{\prime}$ as the reverse primer, as originally described by Nadkarni et al. [64]. Quantification and detection of the amplified products were measured using a DNA-binding dye (SYBR green), rather than the original TaqMan probe. Bacterial copy number was derived from the E. coli DH5a-derived standard curve detailed above. We compared the pan-bacterial copy number per $\mathrm{ml}$ of aspirate with our ability to generate adequate Roche 454FLX 16S rRNA libraries. We utilized the NIH protocols (www.hmpdacc.org) developed for the Human Microbiome Project by performing Roche 454 sequencing of PCR-amplified regions of the V3-V5 region of the 16S rRNA, and defined success as a visually discernable gel band of bar-coded amplicon and by the generation of at least 1,000 reads greater than 250 bp per pooled 1/96th plate. Figure 1 demonstrates the cutoff values for rRNA 454 library generation. The lowest density of bacterial genomes we were able to successfully amplify was 250,000 copies/ml. All 40 patients and 4 of 14 healthy controls had successful microbiome sequencing. Thus, this technology, in conjunction with a measure of bacterial load, appears to hold great promise for improved diagnosis of the respiratory pathogens responsible for severe pneumonia.

\section{Acute Immune Response to Infection}

The immune response to infection is a complex amalgam of the dose and duration of exposure to pathogenassociated molecular patterns (PAMPs), the patient's underlying immune status and medical interventions. Calvano et al. [65] assessed a simple model of infection: the change over $24 \mathrm{~h}$ in genome-wide expression levels of circulating leukocytes after a single exposure of $2 \mathrm{ng}$ per $\mathrm{kg}$ of the PAMP lipopolysaccharide (fig. 2). While over 1,400 genes were significantly regulated with a peak at $4 \mathrm{~h}$, by $24 \mathrm{~h}$ the subjects' leukocyte gene expression had returned 
Fig. 1. Bacterial copy number per ml of tracheal aspirate vs. total number of mapped sequences using Roche 454 sequencing of the V3-V5 region of the bacterial rRNA genome in patients with pneumonia. The lowest bacterial density that resulted in a successful amplification and microbiome analysis was 250,000 copies/ml.

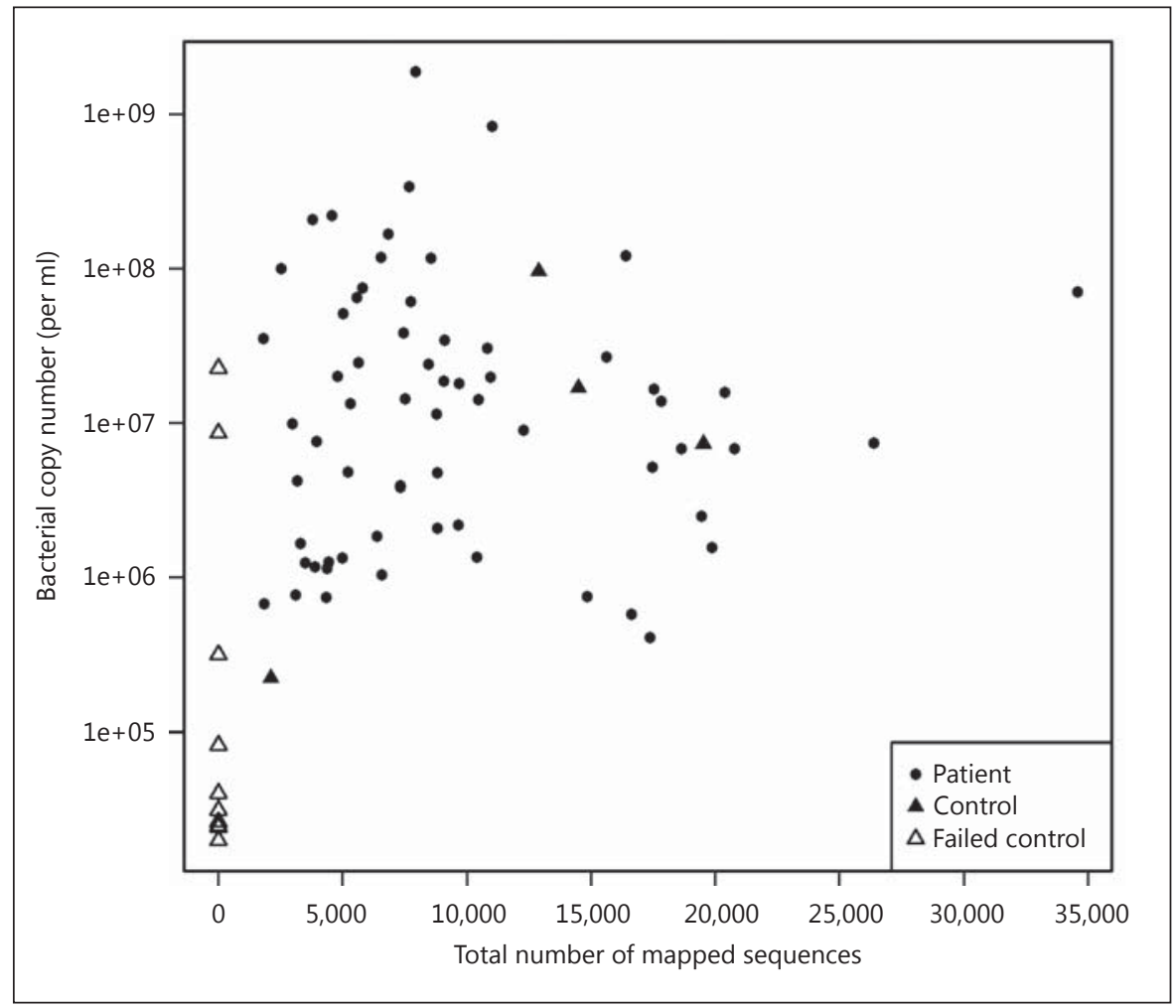

to baseline and the subjects suffered no adverse dysfunction. Consider in distinct contrast patients with severe sepsis in whom the ongoing stimulus of an active infection is characterized by a prolonged hyperinflammatory state that often leads to multiple organ dysfunction. We evaluated the cytokine, chemokine and growth factor response in 362 patients with septic shock. Cytokine concentrations were measured on a Luminex platform and converted to molar values using published sizes for cytokine molecular weights. At median times of 12 and $36 \mathrm{~h}$ following the onset of septic shock, we defined unique patterns of the 39 cytokines, chemokines and growth factors; in many cases, the values were 500 times normal values [4] (fig. 3). In these patients, we sought to understand whether the alteration in cytokines was simply a marker of the severity of underlying illness and chronic health, or whether some component of the immune response was predictive of subsequent mortality independent of clinical variables. Therefore, we assessed common clinical variables (table 2) and the aforementioned cytokines, chemokines and growth factor protein levels at baseline and $24 \mathrm{~h}$ after onset of septic shock in patients $(\mathrm{n}=362)$ from the VASST study.

Meta-Genomics of Sepsis
We used a sophisticated analytic approach to this complex dataset. In brief, the rpart $\mathrm{R}$ package was used for decision tree analysis ( $\mathrm{R}$ version 2.12 ). For classification models (parameter method $=$ class), decision trees were constructed for association with survival at 28 days. Values for complexity parameter and minsplit were based on minimizing the $10 \times$ cross-validated error. Weightings were applied to negative cases (death) as inverse proportion of fraction dead to bias models toward predicting death at the cost of accuracy for predicting positive cases (survival). Weightings for negative cases were 3 for 28day survival. Survival (rate) analysis was performed using rpart (parameter method $=\exp$ ) for patient survival, and days alive and free of renal dysfunction. Statistical differences of survival curves were assessed with the survdiff method of R package survival using a G-rho rank test. Correlation analysis between clinical features and cytokine levels was performed with $\mathrm{R}$ cor.test method from the core stats package, using Kendall tau rank correlation method. The rpart $\mathrm{R}$ package was used for decision tree analysis ( $\mathrm{R}$ version 2.12). Using classification models (parameter method = 'class'), decision trees were constructed for survival outcome at 28 days. Values for complexity parameter and minsplit were based on maximizing the 


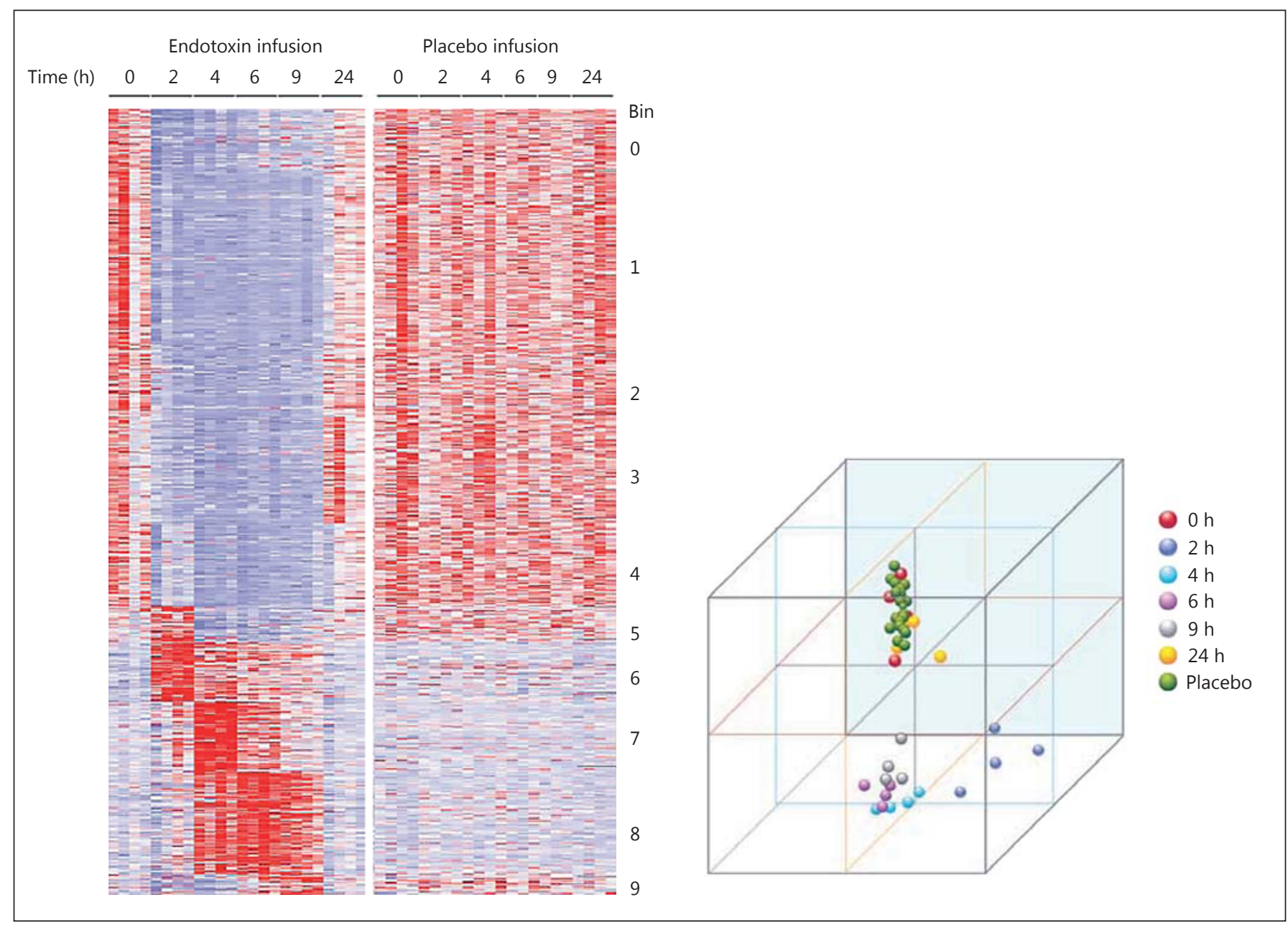

Fig. 2. Samples from 8 healthy volunteers were tested at baseline $(0 \mathrm{~h})$ and 2, 4, 6, 9 and $24 \mathrm{~h}$ after intravenous administration of $2 \mathrm{ng} / \mathrm{kg}$ endotoxin (4 subjects) or vehicle (4 subjects). Significant (false discovery rate of $<0.1 \%)$ probe sets $(5,093)$ were subjected to
K-means clustering into 10 bins (0-9). Probe sets for which the abundance was above the mean are shown in red, below the mean are shown in blue, and equivalent to the mean are in white. Reproduced with permission from Nadkarni et al. [64].
$10 \times$ cross-validated specificity done outside the rpart execution to allow for weightings on survival/nonsurvival classes. For 28-day survival, nonsurvivors comprised $\sim 1 / 3$ of patients and weighting on nonsurvivor cases was 3 ; similarly, day- 5 survival and late survival was approximately $1 / 10$, and weighting on nonsurvivor cases was 10 . For comparison, we used random forest to determine whether performance improvements could be made with more complex models. Survival analysis was performed using rpart (parameter method = 'exp') for patient survival, and days alive and free of renal dysfunction. For survival analysis, the complexity parameter was chosen as the minimum that gave a cross-validated error clearly exceeding the minimum obtained error. A tree analysis was run with $\mathrm{cp}=0.001$; from this rpart model, the minimum error ('xerror') was added to the variance in xerror ('xstd'); the minimum value of $\mathrm{cp}$ giving less xerror than this was chosen. Statistical differences of survival curves were assessed with the 'survdiff method of R package 'survival' using a G-rho rank test.

Correlation analysis between clinical features and cytokine levels was performed with $\mathrm{R}$ cor.test method from stats package, using Kendall tau rank correlation method.

Survival rate survival tree analysis of time of death versus cytokines consists of only three splits; IL-8 measured at $24 \mathrm{~h}$, the difference between CSF2 measured at $24 \mathrm{~h}$ and baseline, and IL-1B at baseline (fig. 4). The resulting four groups of patients had dramatically different mortality: 79 


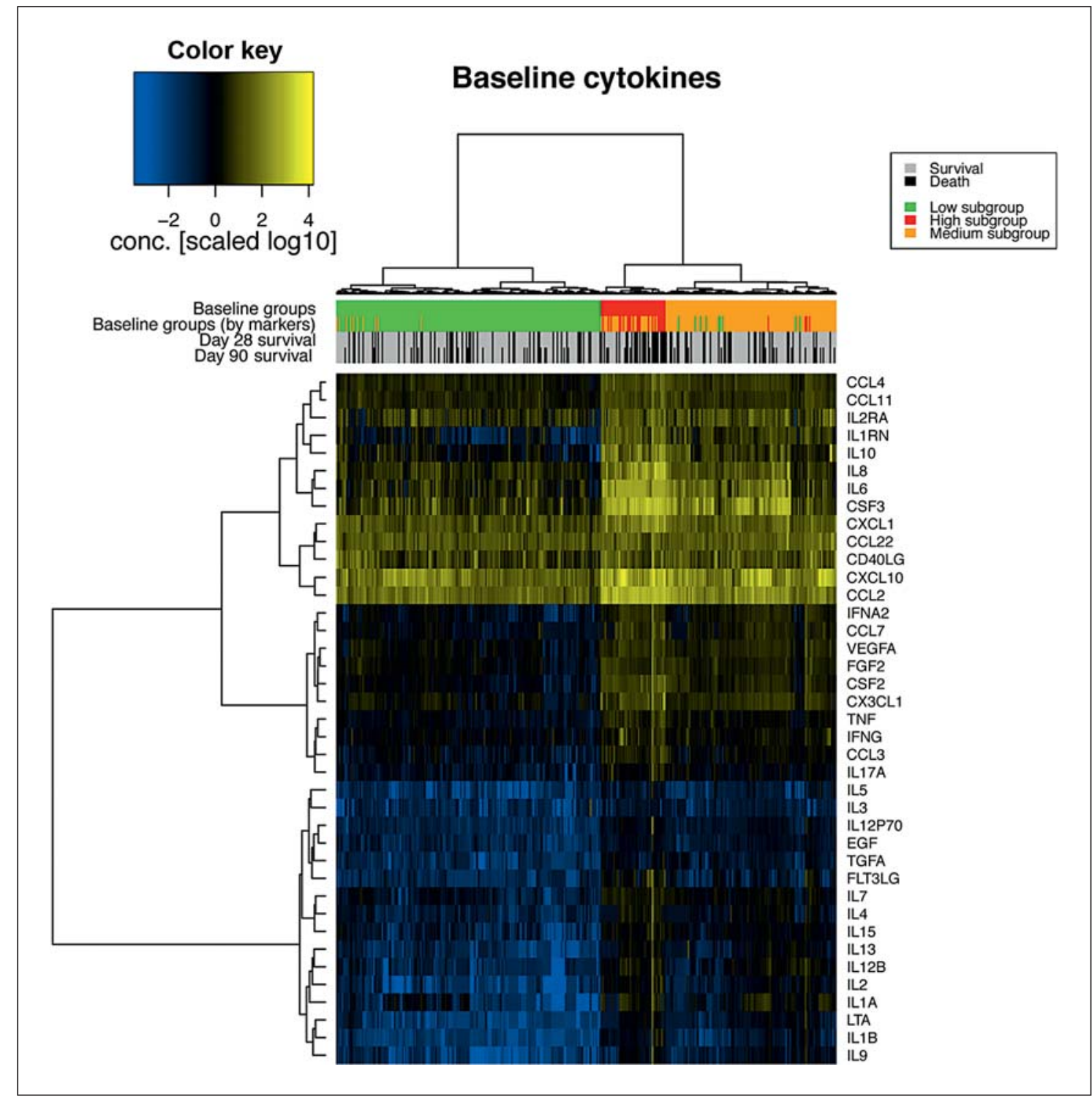

Fig. 3. Cytokine cluster analysis of baseline plasma cytokine, chemokines and growth factor levels in patients who had septic shock. Patient subgrouping, survival and features are indicated on the top colored rows. The baseline groups are the low (green), medium (yellow) and high (red) subgroups; they were identified based on plasma cytokines measured at a median of $12 \mathrm{~h}$ following the onset of severe infection (septic shock). For the most part, one can predict low and medium cytokine subgroups, referred to on the upper track as baseline groups (by markers) through partitioning based upon IL-2 and CSF2, while the high cytokine group requires additional cytokine information. Reproduced with permission from Fjell et al. [4]. and $81 \%$ (leaves 3 and 11), and 26 and 28\% (leaves 4 and $10)$. The survival rate tree survival analysis using all clinical features and cytokine measurements produced a tree with three splits and four leaves. Only one clinical feature (age) could predict survival as well as cytokine levels.

This decision tree analysis incorporating clinical variables and early plasma cytokine, chemokine and growth factor levels in patients with septic shock highlights the importance of the immune response that complements the clinical predictors to model survival (Apache II score) and organ derangement (e.g. acute renal dysfunction). Of all clinical features and cytokine, chemokine and growth factor levels, the strongest distinguishing characteristic was plasma IL-8 measured at $24 \mathrm{~h}$ (the top split in fig. 5). 


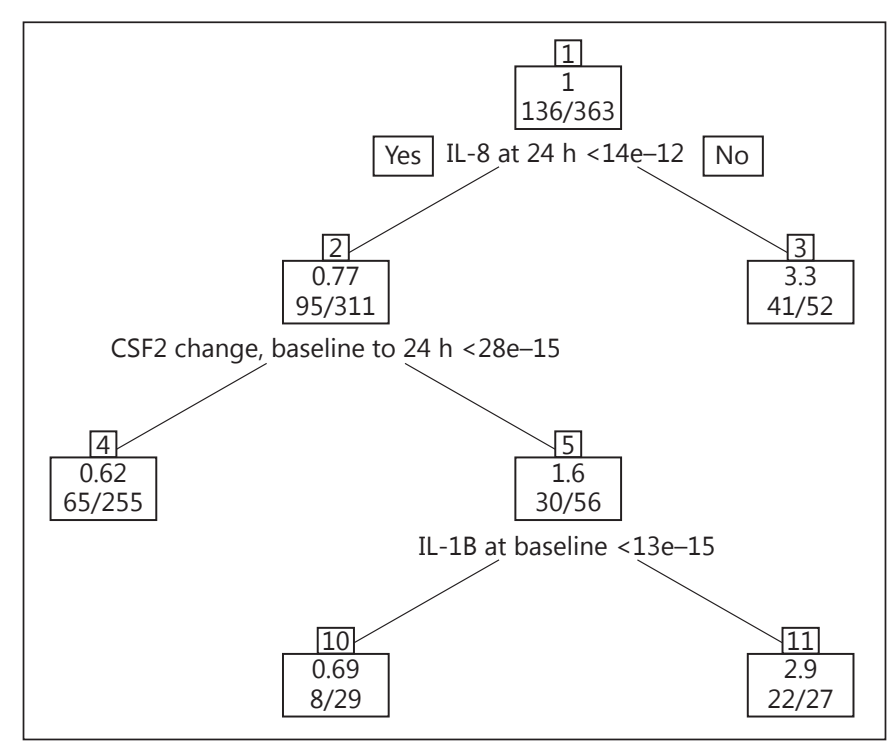

Fig. 4. Decision tree for 28-day survival using cytokine data in patients who had septic shock based on measurement and decision tree analysis plasma levels taken at baseline and at $24 \mathrm{~h}$ of 39 cytokines, chemokines and growth factors. The three numbers in each box are the estimated rates of death scaled to the overall rate, and the number of deaths over the number of patients in the group (e.g. for leaf 3, the number of deaths per time was 3.3 times the overall rate, and 41 of 52 patients died). Splits higher on the tree reflect more important (prominent) factors impacting survival.

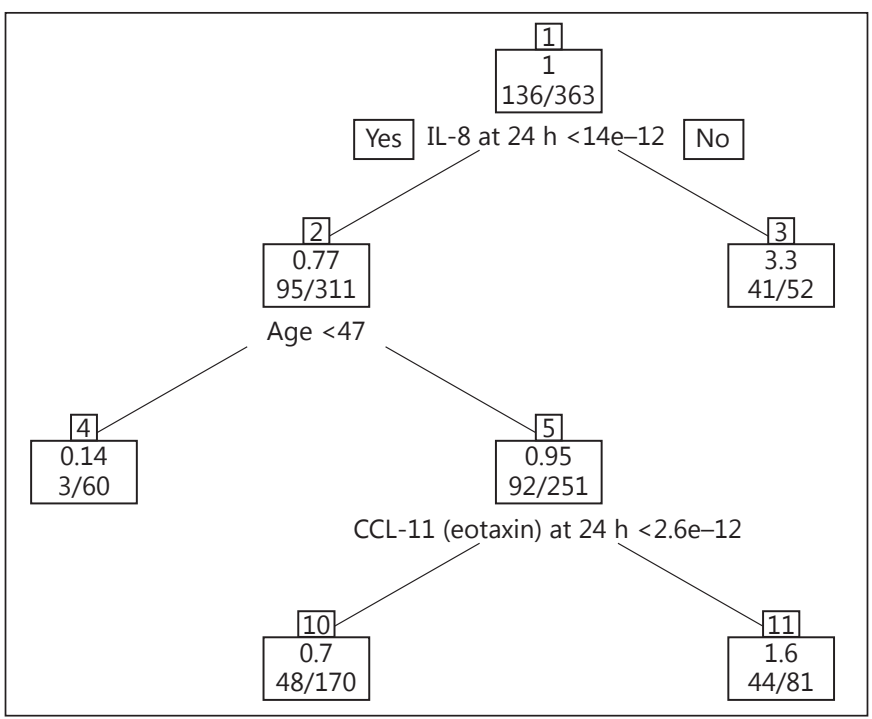

Fig. 5. Decision tree for 28-day survival using baseline clinical variables and cytokine data in patients who had septic shock based on measurement and decision tree analysis plasma levels taken at baseline and at $24 \mathrm{~h}$ of 39 cytokines, chemokines and growth factors. As in figure 4 , the three numbers in each box are the estimated rates of death scaled to the overall rate, and the number of deaths over the number of patients in the group. Splits higher on the tree reflect more important (prominent) factors impacting survival.
Table 2. Clinical variables that were used in outcome modeling combined with plasma levels of 39 cytokines, chemokines and growth factors in patients who had septic shock

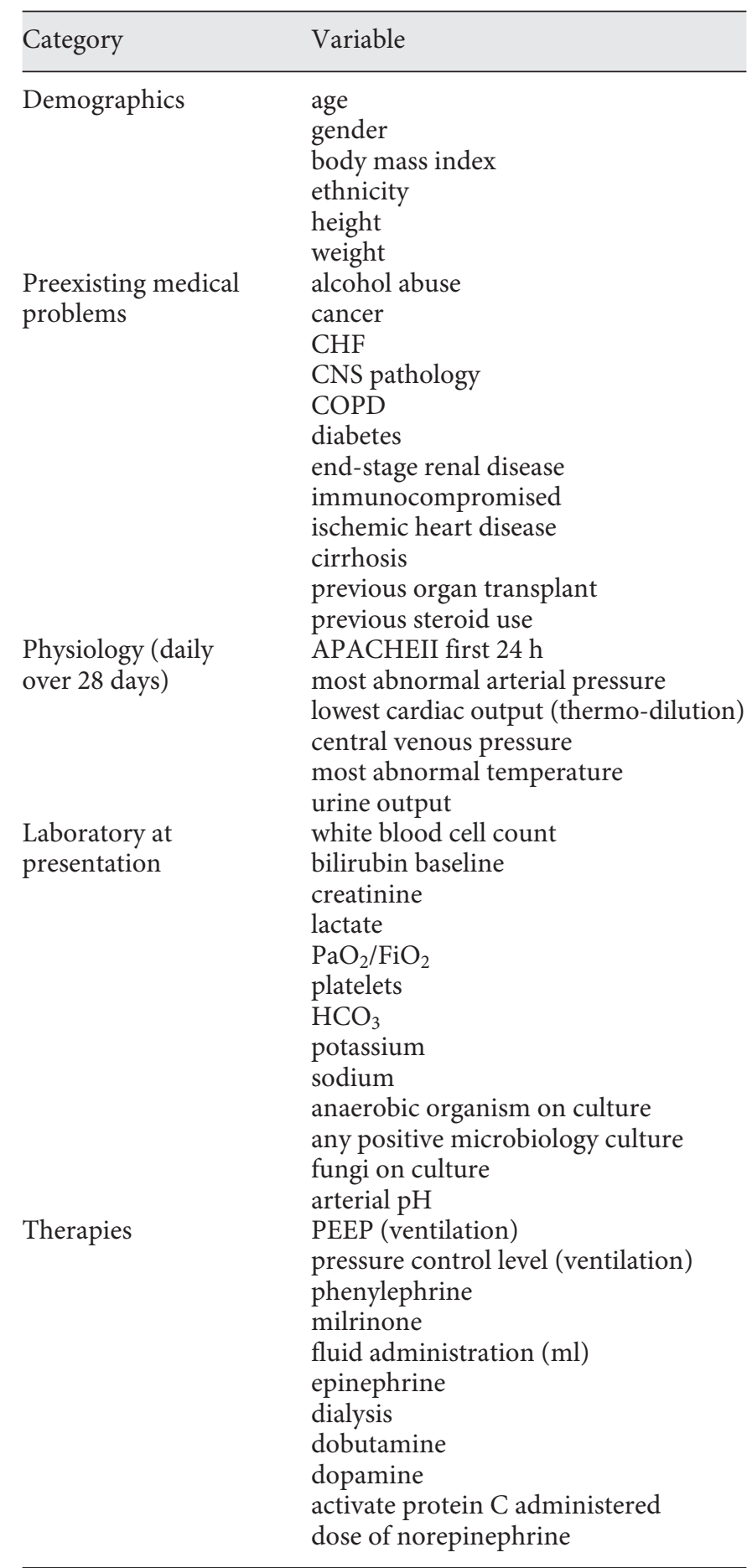


Using a plasma protein survey, which is large by cytokine standards but small given the scope of genomic changes, we were able to define IL-8, CSF2, CCL-11 and IL-1B as important immune regulators of outcome in a prototypical very severe infection, i.e. septic shock.

Currently, RNA sequencing techniques deliver for log scale greater dynamic range than microarray and can identify even single molecules present in a transcriptome, i.e. incredibly high sensitivity. Using this new technology to accurately and quickly identify infecting pathogens and to probe and obtain signatures of the host immune response to infection will likely result in the identification of novel critical regulators of immune function and secondary organ dysfunction and earlier more accurate treatment decisions in severe infections such as septic shock.

\section{Conclusions}

The clinical presentation and outcomes of infection are the result of the complex interplay of host genetics, individual pathogen type and load and finally the genome-wide expression response to infection in circulating leukocytes. The inherited (genetic) component of the meta-genome includes the susceptibility to infection (i.e. that could one day yield diagnostic biomarkers), the pace and extent of the immune response, the risk of later organ dysfunction and death (i.e. prognostic biomarkers) and ability to respond to therapies (i.e. predictive biomarkers). Pathogen load and speciation is a concept not yet used in everyday clinical medicine, but it appears that new nucleic acid technologies will usher in a new era of first treating to rapidly and accurately suppress known pathogens, and second, identification of new and emerging pathogens. The levels and fluctuations of key regulators of acute inflammation (such as IL-8, CSF2, CCL-11 and IL-1B) predict subsequent organ dysfunction and death from severe infection. We anticipate that new targets for therapy in severe sepsis and septic shock will emerge from unbiased genome-wide assessment of the immune response.

\section{Acknowledgements}

Support for this study was obtained through SONRIS CIHR Network grant, Heart and Stroke Foundation, and the National Sanitorium Association. John Boyd is a Michael Smith Foundation for Health Research Scholar.

\section{References}

1 Dellinger RP, Levy MM, Rhodes A, Annane D, Gerlach H, Opal SM, Sevransky JE, Sprung CL, Douglas IS, Jaeschke R, Osborn TM, Nunnally ME, Townsend SR, Reinhart K, Kleinpell RM, Angus DC, Deutschman CS, Machado FR, Rubenfeld GD, Webb SA, Beale RJ, Vincent JL, Moreno R: Surviving Sepsis Campaign: international guidelines for management of severe sepsis and septic shock: 2012. Crit Care Med 2013;41:580637.

2 Russell JA: Management of sepsis. N Engl J Med 2006;355:1699-1713.

- 3 Kellum JA, Kong L, Fink MP, Weissfeld LA, Yealy DM, Pinsky MR, Fine J, Krichevsky A, Delude RL, Angus DC: Understanding the inflammatory cytokine response in pneumonia and sepsis: results of the Genetic and Inflammatory Markers of Sepsis (GenIMS) study. Arch Intern Med 2007;167:1655-1663.

-4 Fjell CD, Thair S, Hsu JL, Walley KR, Russell JA, Boyd J: Cytokines and signaling molecules predict clinical outcomes in sepsis. PLoS One 2013;8:e79207.
5 Russell JA, Fjell C, Hsu JL, Lee T, Boyd J, Thair S, Singer J, Patterson AJ, Walley KR: Vasopressin compared with norepinephrine augments the decline of plasma cytokine levels in septic shock. Am J Respir Crit Care Med 2013; 188:356-364.

-6 Hotchkiss RS, Tinsley KW, Swanson PE, Schmieg RE Jr, Hui JJ, Chang KC, Osborne DF, Freeman BD, Cobb JP, Buchman TG, Karl IE: Sepsis-induced apoptosis causes progressive profound depletion of B and CD4+ T lymphocytes in humans. J Immunol 2001; 166:6952-6963.

7 Venet F, Chung CS, Kherouf H, Geeraert A, Malcus C, Poitevin F, Bohe J, Lepape A, Ayala A, Monneret G: Increased circulating regulatory T cells $(\mathrm{CD} 4+\mathrm{CD} 25+\mathrm{CD} 127-)$ contribute to lymphocyte anergy in septic shock patients. Intensive Care Med 2009;35:678686.

8 Alejandria MM, Lansang MA, Dans LF, Mantaring JB: Intravenous immunoglobulin for treating sepsis and septic shock. Cochrane Database Syst Rev 2002;CD001090.
9 Werdan K, Pilz G, Bujdoso O, Fraunberger P, Neeser G, Schmieder RE, Viell B, Marget W, Seewald M, Walger P, Stuttmann R, Speichermann N, Peckelsen C, Kurowski V, Osterhues HH, Verner L, Neumann R, Muller-Werdan $\mathrm{U}$ : Score-based immunoglobulin $\mathrm{G}$ therapy of patients with sepsis: the SBITS study. Crit Care Med 2007;35:2693-2701.

10 Brun-Buisson C, Doyon F, Carlet J, Dellamonica P, Gouin F, Lepoutre A, Mercier JC, Offenstadt G, Regnier B: Incidence, risk factors, and outcome of severe sepsis and septic shock in adults. A multicenter prospective study in intensive care units. French ICU group for severe sepsis. JAMA 1995;274:968974.

11 Wang HE, Shapiro NI, Angus DC, Yealy DM: National estimates of severe sepsis in United States emergency departments. Crit Care Med 2007;35:1928-1936.

12 McCloskey RV, Straube RC, Sanders C, Smith SM, Smith CR: Treatment of septic shock with human monoclonal antibody HA-1A. A randomized, double-blind, placebo-controlled trial. CHESS trial study group. Ann Intern Med 1994;121:1-5. 
13 Angus DC, Birmingham MC, Balk RA, Scannon PJ, Collins D, Kruse JA, Graham DR, Dedhia HV, Homann S, MacIntyre N: E5 murine monoclonal antiendotoxin antibody in gram-negative sepsis: a randomized controlled trial. E5 Study Investigators. JAMA 2000;283:1723-1730.

- 14 Albertson TE, Panacek EA, MacArthur RD, Johnson SB, Benjamin E, Matuschak GM, Zaloga G, Maki D, Silverstein J, Tobias JK, Haenftling K, Black G, Cowens JW: Multicenter evaluation of a human monoclonal antibody to enterobacteriaceae common antigen in patients with Gram-negative sepsis. Crit Care Med 2003;31:419-427.

15 Abraham E, Glauser MP, Butler T, Garbino J, Gelmont D, Laterre PF, Kudsk K, Bruining HA, Otto C, Tobin E, Zwingelstein C, Lesslauer W, Leighton A: P55 tumor necrosis factor receptor fusion protein in the treatment of patients with severe sepsis and septic shock. A randomized controlled multicenter trial. Ro 45-2081 Study Group. JAMA 1997;277:15311538.

16 Abraham E, Laterre PF, Garbino J, Pingleton S, Butler T, Dugernier T, Margolis B, Kudsk K, Zimmerli W, Anderson P, Reynaert M, Lew D, Lesslauer W, Passe S, Cooper P, Burdeska A, Modi M, Leighton A, Salgo M, Van der Auwera P: Lenercept (p55 tumor necrosis factor receptor fusion protein) in severe sepsis and early septic shock: a randomized, double-blind, placebo-controlled, multicenter phase III trial with 1,342 patients. Crit Care Med 2001;29:503-510.

-17 Abraham E, Wunderink R, Silverman H, Perl TM, Nasraway S, Levy H, Bone R, Wenzel RP, Balk R, Allred R, et al: Efficacy and safety of monoclonal antibody to human tumor necrosis factor alpha in patients with sepsis syndrome. A randomized, controlled, doubleblind, multicenter clinical trial. TNF-alpha MAb Sepsis Study Group. JAMA 1995;273: 934-941.

18 Cohen J, Carlet J: INTERSEPT: an international, multicenter, placebo-controlled trial of monoclonal antibody to human tumor necrosis factor-alpha in patients with sepsis. International Sepsis Trial Study Group. Crit Care Med 1996;24:1431-1440.

- 19 Panacek EA, Marshall JC, Albertson TE, Johnson DH, Johnson S, MacArthur RD, Miller M, Barchuk WT, Fischkoff S, Kaul M, Teoh L, Van Meter L, Daum L, Lemeshow S, Hicklin G, Doig C: Efficacy and safety of the monoclonal anti-tumor necrosis factor antibody $\mathrm{F}\left(\mathrm{ab}^{\prime}\right) 2$ fragment afelimomab in patients with severe sepsis and elevated interleukin-6 levels. Crit Care Med 2004;32:21732182.

-20 Sprung CL, Caralis PV, Marcial EH, Pierce M, Gelbard MA, Long WM, Duncan RC, Tendler MD, Karpf M: The effects of high-dose corticosteroids in patients with septic shock. A prospective, controlled study. N Engl J Med 1984;311:1137-1143.
21 Effect of high-dose glucocorticoid therapy on mortality in patients with clinical signs of systemic sepsis. The Veterans Administration Systemic Sepsis Cooperative Study Group. N Engl J Med 1987;317:659-665.

22 Bone RC, Fisher CJ Jr, Clemmer TP, Slotman GJ, Metz CA, Balk RA: A controlled clinical trial of high-dose methylprednisolone in the treatment of severe sepsis and septic shock. N Engl J Med 1987;317:653-658.

23 Annane D, Sebille V, Charpentier C, Bollaert PE, Francois B, Korach JM, Capellier G, Cohen Y, Azoulay E, Troche G, ChaumetRiffaud P, Bellissant E: Effect of treatment with low doses of hydrocortisone and fludrocortisone on mortality in patients with septic shock. JAMA 2002;288:862-871.

24 Sprung CL, Annane D, Keh D, Moreno R, Singer M, Freivogel K, Weiss YG, Benbenishty J, Kalenka A, Forst H, Laterre PF, Reinhart $\mathrm{K}$, Cuthbertson $\mathrm{BH}$, Payen $\mathrm{D}$, Briegel J: Hydrocortisone therapy for patients with septic shock. N Engl J Med 2008;358:111-124.

25 Dellinger RP, Levy MM, Rhodes A, Annane D, Gerlach H, Opal SM, Sevransky JE, Sprung CL, Douglas IS, Jaeschke R, Osborn TM, Nunnally ME, Townsend SR, Reinhart K, Kleinpell RM, Angus DC, Deutschman CS, Machado FR, Rubenfeld GD, Webb S, Beale RJ, Vincent JL, Moreno R: Surviving Sepsis Campaign: international guidelines for management of severe sepsis and septic shock, 2012. Intensive Care Med 2013;39:165-228.

26 Russell JA, Walley KR, Singer J, Gordon AC, Hebert PC, Cooper DJ, Holmes CL, Mehta S, Granton JT, Storms MM, Cook DJ, Presneill JJ, Ayers D: Vasopressin versus norepinephrine infusion in patients with septic shock. $\mathrm{N}$ Engl J Med 2008;358:877-887.

27 Kumar A, Safdar N, Kethireddy S, Chateau D: A survival benefit of combination antibiotic therapy for serious infections associated with sepsis and septic shock is contingent only on the risk of death: a meta-analytic/meta-regression study. Crit Care Med 2010;38:16511664.

28 Kumar A: Early antimicrobial therapy in severe sepsis and septic shock. Curr Infect Dis Rep 2010;12:336-344.

$\checkmark 29$ Kumar A: Optimizing antimicrobial therapy in sepsis and septic shock. Crit Care Clin 2009;25:733-751, viii.

30 Sharma S, Kumar A: Antimicrobial management of sepsis and septic shock. Clin Chest Med 2008;29:677-687, ix.

31 Schloissnig S, Arumugam M, Sunagawa S, Mitreva M, Tap J, Zhu A, Waller A, Mende DR, Kultima JR, Martin J, Kota K, Sunyaev SR, Weinstock GM, Bork P: Genomic variation landscape of the human gut microbiome. Nature 2013;493:45-50.
32 Yatsunenko T, Rey FE, Manary MJ, Trehan I, Dominguez-Bello MG, Contreras M, Magris M, Hidalgo G, Baldassano RN, Anokhin AP, Heath AC, Warner B, Reeder J, Kuczynski J, Caporaso JG, Lozupone CA, Lauber C, Clemente JC, Knights D, Knight R, Gordon JI: Human gut microbiome viewed across age and geography. Nature 2012;486:222-227.

33 Gravitz L: Microbiome: the critters within. Nature 2012;485:S12-S13.

34 Sutherland AM, Walley KR, Russell JA: Polymorphisms in CD14, mannose-binding lectin, and Toll-like receptor-2 are associated with increased prevalence of infection in critically ill adults. Crit Care Med 2005;33:638644.

-35 Nakada TA, Russell JA, Boyd JH, Walley KR: Ill7a genetic variation is associated with altered susceptibility to gram-positive infection and mortality of severe sepsis. Crit Care 2011; 15:R254.

- 36 Sutherland AM, Walley KR, Nakada TA, Sham AH, Wurfel MM, Russell JA: A nonsynonymous polymorphism of IRAK4 associated with increased prevalence of Gram-positive infection and decreased response to Toll-like receptor ligands. J Innate Immun 2011;3:447458.

37 Dale AP, Read RC: Genetic susceptibility to meningococcal infection. Expert Rev Anti Infect Ther 2013;11:187-199.

38 Pontillo A, Carvalho MS, Kamada AJ, Moura R, Schindler HC, Duarte AJ, Crovella S: Susceptibility to mycobacterium tuberculosis infection in HIV-positive patients is associated with CARD8 genetic variant. J Acquir Immune Defic Syndr 2013;63:147-151.

- 39 Sutherland AM, Walley KR, Manocha S, Russell JA: The association of interleukin 6 haplotype clades with mortality in critically ill adults. Arch Intern Med 2005;165:75-82.

40 Walley KR, Russell JA: Protein c-1641 AA is associated with decreased survival and more organ dysfunction in severe sepsis. Crit Care Med 2007;35:12-17.

-41 Russell JA, Wellman H, Walley KR: Protein C rs2069912 C allele is associated with increased mortality from severe sepsis in North Americans of East Asian ancestry. Hum Genet 2008; 123:661-663.

42 Thair SA, Walley KR, Nakada TA, McConechy MK, Boyd JH, Wellman H, Russell JA: A single nucleotide polymorphism in NFkappaB inducing kinase is associated with mortality in septic shock. J Immunol 2011; 186:2321-2328.

43 Wacharasint P, Nakada TA, Boyd JH, Russell JA, Walley KR: AA genotype of IL-8 -251A/T is associated with low $\mathrm{PaO}(2) / \mathrm{FiO}(2)$ in critically ill patients and with increased IL-8 expression. Respirology 2012;17:1253-1260.

- 44 Nakada TA, Russell JA, Boyd JH, AguirreHernandez R, Thain KR, Thair SA, Nakada E, McConechy M, Walley KR: Beta2-adrenergic receptor gene polymorphism is associated with mortality in septic shock. Am J Respir Crit Care Med 2010;181:143-149. 
-45 Nakada TA, Russell JA, Wellman H, Boyd JH, Nakada E, Thain KR, Thair SA, Hirasawa H, Oda S, Walley KR: Leucyl/cystinyl aminopeptidase gene variants in septic shock. Chest 2011;139:1042-1049.

46 Nakada TA, Russell JA, Boyd JH, McLaughlin L, Nakada E, Thair SA, Hirasawa H, Oda S, Walley KR: Association of angiotensin II type 1 receptor-associated protein gene polymorphism with increased mortality in septic shock. Crit Care Med 2011;39:1641-1648.

-47 Reinhart K, Bauer M, Riedemann NC, Hartog CS: New approaches to sepsis: molecular diagnostics and biomarkers. Clin Microbiol Rev 2012;25:609-634

48 Paolucci M, Landini MP, Sambri V: Conventional and molecular techniques for the early diagnosis of bacteraemia. Int J Antimicrob Agents 2010;36(suppl 2):S6-S16.

-49 Kim DM, Jung SI, Jang HC, Lee CS, Lee SH, Yun NR, Neupane GP, Park KH: Vibrio vulnificus DNA load and mortality. J Clin Microbiol 2011;49:413-415.

50 Ho YC, Chang SC, Lin SR, Wang WK: High levels of mecA DNA detected by a quantitative real-time PCR assay are associated with mortality in patients with methicillin-resistant Staphylococcus aureus bacteremia. J Clin Microbiol 2009;47:1443-1451.

51 Hackett SJ, Guiver M, Marsh J, Sills JA, Thomson AP, Kaczmarski EB, Hart CA: Meningococcal bacterial DNA load at presentation correlates with disease severity. Arch Dis Childhood 2002;86:44-46.

-52 Darton T, Guiver M, Naylor S, Jack DL, Kaczmarski EB, Borrow R, Read RC: Severity of meningococcal disease associated with genomic bacterial load. Clin Infect Dis 2009;48: 587-594.

53 Kirkbright S, Fatovich D, Kee C, Kay I, Flexman J, Pryce TM, Waterer GW: Quantitative rt-PCR holds promise as a screening tool for patients with severe sepsis. Emerg Med Australas 2011;23:502-506.
Esparcia O, Montemayor M, Ginovart G, Pomar V, Soriano G, Pericas R, Gurgui M, Sulleiro E, Prats G, Navarro F, Coll P: Diagnostic accuracy of a 16s ribosomal DNA gene-based molecular technique (rt-PCR, microarray, and sequencing) for bacterial meningitis, early-onset neonatal sepsis, and spontaneous bacterial peritonitis. Diagn Microbiol Infect Dis 2011;69:153-160.

55 Pasqualini L, Mencacci A, Leli C, Montagna P, Cardaccia A, Cenci E, Montecarlo I, Pirro M, di Filippo F, Cistaro E, Schillaci G, Bistoni F, Mannarino E: Diagnostic performance of a multiple real-time PCR assay in patients with suspected sepsis hospitalized in an internal medicine ward. J Clin Microbiol 2012;50: 1285-1288.

56 Chuang YC, Chang SC, Wang WK: Using the rate of bacterial clearance determined by realtime polymerase chain reaction as a timely surrogate marker to evaluate the appropriateness of antibiotic usage in critical patients with Acinetobacter baumannii bacteremia. Crit Care Med 2012;40:2273-2280.

57 Dark P, Chadwick P, Warhurst G: Detecting sepsis-associated bloodstream infection acquired in intensive care using multi-pathogen real-time PCR. J Infect 2009;59:296-298.

58 Dierkes C, Ehrenstein B, Siebig S, Linde HJ, Reischl U, Salzberger B: Clinical impact of a commercially available multiplex PCR system for rapid detection of pathogens in patients with presumed sepsis. BMC Infect Dis 2009; 9:126.
59 Maubon D, Hamidfar-Roy R, Courby S, Ve$\sin$ A, Maurin M, Pavese P, Ravanel N, Bulabois CE, Brion JP, Pelloux H, Timsit JF: Therapeutic impact and diagnostic performance of multiplex PCR in patients with malignancies and suspected sepsis. J Infect 2010;61:335342 .

60 Tran NK, Greenhalgh DG, Palmieri TL, Kost GJ: Multiplex PCR pathogen detection in two severely burned patients with suspected septicemia. J Burn Care Res 2011;32:e172-e177.

-61 Broecker F, Kube M, Klumpp J, Schuppler M, Biedermann L, Hecht J, Hombach M, Keller PM, Rogler G, Moelling K: Analysis of the intestinal microbiome of a recovered Clostridium difficile patient after fecal transplantation. Digestion 2013;88:243-251.

-62 Neville BA, Sheridan PO, Harris HM, Coughlan S, Flint HJ, Duncan SH, Jeffery IB, Claesson MJ, Ross RP, Scott KP, O’Toole PW: Proinflammatory flagellin proteins of prevalent motile commensal bacteria are variably abundant in the intestinal microbiome of elderly humans. PLoS One 2013;8:e68919.

63 Stringer AM, Al-Dasooqi N, Bowen JM, Tan TH, Radzuan M, Logan RM, Mayo B, Keefe DM, Gibson RJ: Biomarkers of chemotherapy-induced diarrhoea: a clinical study of intestinal microbiome alterations, inflammation and circulating matrix metalloproteinases. Support Care Cancer 2013;21: 1843-1852.

64 Nadkarni MA, Martin FE, Jacques NA, Hunter N: Determination of bacterial load by realtime PCR using a broad-range (universal) probe and primers set. Microbiology 2002; 148:257-266.

65 Calvano SE, Xiao W, Richards DR, Felciano RM, Baker HV, Cho RJ, Chen RO, Brownstein BH, Cobb JP, Tschoeke SK, Miller-Graziano C, Moldawer LL, Mindrinos MN, Davis RW, Tompkins RG, Lowry SF: A networkbased analysis of systemic inflammation in humans. Nature 2005;437:1032-1037. 